\title{
A abordagem fenomenológica e sua relação com mapas mentais no processo de ensino aprendizagem em geografia
}

\author{
The phenomenological approach and its relation with mental maps in the \\ teaching learning process in geography
}

\author{
Raissa Brum Gonçalves de Ávila'; Rosangela Lurdes Spironello"
}

\begin{abstract}
RESUMO
Este artigo tem como objetivos desenvolver um levantamento e análise das referências que abordam a relação entre as categorias de análise espacial, paisagem e lugar, na fenomenologia e as estratégias metodológicas por meio da elaboração de mapas mentais no ensino de Geografia. Metodologicamente, a pesquisa buscou inicialmente, realizar um levantamento e caracterização dos documentos a serem analisados. O filtro de seleção desses documentos deu-se a partir de materiais que constituíram a totalidade de artigos em periódicos da base de dados Qualis Capes (2016), na área da Geografia e Educação. Em seguida, fez-se uma análise desses referenciais, considerando a relação da tríade (paisagem/lugar-fenomenologiamapas mentais). Os resultados estão divididos em três conceitos estruturantes: 1) A Perspectiva da Geografia Fenomenológica em que é abordado o pensamento deste método de análise para a Geografia; 2) A Percepção da paisagem e lugar com o foco da Geografia humanista; e 3) Elaboração de mapas mentais no ensino de Geografia, o qual considera as percepções e representações sociais no processo de ensino de Geografia. Este estudo reforçou a ideia de que a utilização de aporte metodológico da representação, por meio dos mapas mentais, são ferramentas úteis para os educadores de Geografia realizarem diagnósticos do estudo do lugar, da paisagem, podendo fomentar de forma instigante os estudos de Geografia em sala de aula.
\end{abstract}

Palavras-chave: ensino de Geografia; fenomenologia; lugar; mapas mentais; paisagem

\begin{abstract}
This article aims to develop a survey and analysis of references that approach the relation between the categories of spatial analysis, landscape and site, in phenomenology and methodological strategies through the elaboration of mental maps in the Geography teaching. Methodologically, the research initially sought to conduct a survey and characterization of the documents to be analyzed. The filter of selection to these documents was based from materials that composed the totality of the articles in journals from the Qualis Capes database (2016), in the area of Geography and Education. Afterwards, it was done an analysis of these references, considering the relation of the triad (landscape/site-phenomenology-mental maps). The results are divided into three structured concepts: 1) The Phenomenological Geography Perspective in which is approached the thought of this method of analysis for Geography; 2) The Perception of landscape and site with a focus on humanistic Geography; and 3) Elaboration of mental maps in Geography teaching, which considers the social perceptions and representations in the process of teaching Geography. This study strengthen the ideia that the utilization of methodological support of representation, throught mental maps, are useful tools for Geography educators to carry out diagnoses of the study site, landscape, being able to foment in an instigating way the studies of Geography in the classroom.
\end{abstract}

Keywords: Geography teaching; phenomenology; site; mental maps; landscape

I Universidade Federal de Pelotas, RS, Brasil - http://orcid.org/0000-0002-3359-0196 - raissaavila@yahoo.com.br " Universidade Federal de Pelotas, RS, Brasil - http://orcid.org/0000-0001-9272-2040 - spironello@gmail.com 


\section{INTRODUÇÃO}

A presente proposta que se apresenta é o reflexo das leituras, discussões e reflexões que foram desenvolvidas por meio da pesquisa no Curso de Pós-Graduação em Geografia (Mestrado) da Universidade Y, com foco central na abordagem fenomenológica e sua relação com a cartografia escolar no processo de ensino/aprendizagem em Geografia.

Nessa perspectiva, a referida proposta configura-se no sentido de trazer algumas contribuições, por meio de pesquisa documental, acerca da Geografia fenomenológica com foco na percepção da paisagem e do lugar como categorias de análise espacial e como os mapas mentais podem contribuir como estratégias metodológicas no ensino de Geografia. Diante disto, o enfoque utilizado é o pensamento fenomenológico e humanista para a ciência geográfica. Apresenta-se a paisagem e o lugar a partir da percepção, como processos e relações experienciais, isto é, a respeito do olhar subjetivo, do abstrato, sentimentos, simbólicos e as relações espaciais sociais.

Desta maneira, com embasamento teórico, esta proposta “(...) privilegia o singular e não o particular ou o universal e, ao invés da explicação, tem na compreensão a base de inteligibilidade do mundo real" (CÔRREA, 2000 p. 30). Em vista disso, o raciocínio principal da especialidade do humanismo é a subjetividade na interpretação do fenômeno.

A subjetividade do saber é um dos traços mais marcantes do humanismo e deriva diretamente desta concepção antropocêntrica. Na geografia, isto significa que a definição de numa espacialidade não pode ser estabelecida através da objetivação de uma ciência racionalista (GOMES, 2010, p.310).

Com base na perspectiva mencionada, percebe-se a importância ao trabalhar os conceitos de paisagem e lugar na Geografia humanista, seguindo algumas linhas desenvolvidas de estudo que enfatizam a percepção e a experienciação do ambiente. Também torna-se importante destacar a relevância da representação espacial por 
meio dos mapas mentais como aporte metodológico, pois os mesmos são capazes de produzir subjetividades ao expor as singularidades dos sujeitos, mostrando-se como alternativas no ensino de Geografia para analisar a paisagem e o lugar, pois, quando cartografada, desvenda a concepção do seu autor como finalidade de descrever a experiência humana no espaço. Sendo assim, esta abordagem pautada na Geografia humanista traz à tona a modo de clarificar o significado dos símbolos, sentimentos, valores do sujeito para com a paisagem.

A representação espacial significa, aqui, mais do que uma simples indicação da localização dos fenômenos; ela permite, com efeito, resgatar a inteligibilidade que os fatos espaciais adquirem quando são compreendidos a partir de seus contextos próprios. (GOMES, 2010, p. 312)

Assim, como suporte para a construção e desenvolvimento da temática são apresentados alguns autores que deram luz ao pensamento geográfico fenomenológico, os quais serviram de sustentáculo para nosso levantamento documental, sendo: o geógrafo Yi-Fu Tuan (2013), os filósofos Maurice Merleau-Ponty (1999), Edmund Husserl (2002), que mais pontualmente dizem respeito aos conhecimentos sobre a análise de categoria espacial paisagem e lugar a partir do enfoque fenomenológico.

Por entender que este pensamento fenomenológico articula com a perspectiva experiencial, simbólica, subjetiva de ressignificação espacial - própria da relação humana com o espaço -, torna-se ainda mais relevante abordar as categorias de análise espacial paisagem e lugar com o viés da Geografia humanista na perspectiva fenomenológica. É a partir desse movimento que a pesquisa, aqui realizada, visa um levantamento e análise sobre percepção da paisagem e lugar (através da elaboração de mapas mentais na cartografia humanista e cultural) e vislumbra uma alternativa para representação da paisagem, aguçando novas formas e possibilidades de poder reinterpretar os valores de mundo.

Os mapas mentais, por exemplo, podem ser usados no ambiente escolar na disciplina de Geografia como instrumento de análise visual da paisagem e do lugar, 
pois os mesmos originam os processos de significação e permitem a leitura da sociedade sobre o espaço a partir da sua singularidade, levando em consideração que cada sujeito vê e interpreta o ambiente de forma distinta. Esta forma de representação cartográfica é uma linguagem simbólica e depende da percepção humana, tendo por finalidade a compreensão por diferentes olhares geográficos sobre o espaço.

Ainda com relação aos mapas mentais, pode-se dizer que estes são representações informais sociais de uma paisagem ou de um lugar, através de uma imagem ou da vida cotidiana surgindo do simbólico, de modo que perpassam por construções mentais decorrentes da apreensão de significados. Assim, esta cartografia humanista no ensino de Geografia é capaz de captar as percepções produzidas pelos escolares, pois são amplas linguagens das diferentes realidades sociais do indivíduo com o ambiente. Neste viés, tais representações nada mais são do que manifestações culturais que revelam uma maneira de melhor entender e mesmo compreender a vida singular de cada sujeito da produção do espaço, a partir mencionado constructo de mapas mentais.

Como forma de orientar nossa linha de raciocínio e na aspiração de atingir os objetivos dessa proposta, buscou-se conduzir a revisão sistemática da literatura a partir de três conceitos estruturantes para o trabalho: perspectiva fenomenológica; percepção da paisagem e lugar; e elaboração de mapas mentais. No que se refere à estruturação do texto, este apresenta-se em quatro partes divididas no seguintes itens: a) Metodologia de busca, que contempla aporte teórico e metodológico; b) Resultados, os quais trazem as principais abordagens sobre o tema com os subtítulos: A Perspectiva da Geografia Fenomenológica no qual será abordado o pensamento deste método de análise para geografia; em seguida: A Percepção da paisagem e lugar que apresenta o foco da geografia humanista com base na filosofia da fenomenologia e, por último: Elaboração de mapas mentais no ensino de Geografia, no qual se concebe a elaboração de mapas mentais como instrumento teórico-metodológico que, por sua vez, consideram as percepções e reapresentações sociais no processo de ensino de 
Geografia, e sendo um movimento surgido na Geografia fenomenológica; c) Discussão, e, para encerramento, d) Conclusão.

\section{METODOLOGIA DE BUSCA}

O trabalho caracteriza-se como um estudo do tipo de "Revisão sistemática de literatura" tendo por objetivo analisar a produção acadêmica do tema, por meio de pesquisa documental. Desta maneira, no primeiro momento realizou-se um levantamento e caracterização dos documentos a serem analisados, apresentando a seguinte orientação:

1. Delimitação e localização das fontes documentais: o filtro de seleção se deu a partir de documentos que constituíram a análise em sua totalidade de artigos em periódicos na área da Geografia e educação.

2. Localização e delimitação dos bancos de pesquisas: bancos digitais em periódicos da base de dados Qualis Capes (2016), e referências bibliográficas de trabalhos da área.

3. Estabelecimento de critérios, filtros de seleção do material: existência de palavras-chave utilizadas: percepção da paisagem e lugar, Geografia e fenomenologia, mapas mentais e no ensino de Geografia que caracterizam o tema fenomenologia e paisagem: os mapas mentais como ferramenta de ensino de Geografia.

4. Levantamento dos documentos: artigos da base da Qualis Capes (2016).

5. Leitura preliminar do material levantado, visando identificar 10 artigos para conseguir desenvolver esta revisão bibliográfica e confirmar relação com o tema objetivado: leitura dos resumos e palavras-chave;

Resultado: os artigos encontrados e selecionados a partir da leitura do resumo foram: Almeida (2011); Bertin (2013); Claro e Pereira (2015); Marandola (2005); Paula (2014); Lima e Kozel (2009); Archela e Gratão e Trostdorf (2004); Oliveira (2000); Gonçalves (2007); e Pereira e Seemann (2014). Conforme mostra quadro 1. 
Quadro 1- Artigos analisados

\begin{tabular}{|c|c|c|}
\hline AUTORES & ARTIGO & REVISTA \\
\hline Oliveira (2000) & $\begin{array}{l}\text { Percepção da paisagem geográfica: } \\
\text { Piaget, Gibson e Tuan. }\end{array}$ & Geografia, Rio Claro \\
\hline $\begin{array}{l}\text { Archela e Gratão e } \\
\text { Trostdorf (2004) }\end{array}$ & $\begin{array}{l}\text { O lugar dos mapas mentais na } \\
\text { representação do lugar. }\end{array}$ & Geografia - Londrina \\
\hline Marandola (2005) & $\begin{array}{l}\text { Humanismo e a Abordagem Cultural em } \\
\text { Geografia. }\end{array}$ & Geografia, Rio Claro \\
\hline Gonçalves (2007) & $\begin{array}{l}\text { Repensando o lugar na geografia: } \\
\text { espaços- tempos cotidiano e } \\
\text { conhecimentos e práticas sociais. }\end{array}$ & Geografia, Rio Claro \\
\hline Lima e Kozel (2009) & $\begin{array}{l}\text { Lugar e mapa mental: uma análise } \\
\text { possível. }\end{array}$ & Geografia- Londrina \\
\hline Almeida (2011) & $\begin{array}{l}\text { Abordagem fenomenológica } \\
\text { transcendental e existencial na geografia: } \\
\text { As bases para o entendimento do espaço } \\
\text { vivido. }\end{array}$ & Revista Geografar \\
\hline Bertin (2013) & $\begin{array}{l}\text { Geografia Humanística- O papel das } \\
\text { Representações Sociais e Espaciais em } \\
\text { Manifestações Contemporâneas. }\end{array}$ & Revista Geografar \\
\hline Paula (2014) & $\begin{array}{l}\text { Geografia Humanista e Fenomenologia: } \\
\text { contribuições Francófonas no L'espace } \\
\text { Geografaphique. }\end{array}$ & Geografia, Rio Claro \\
\hline $\begin{array}{l}\text { Pereira e Seemann } \\
(2014)\end{array}$ & $\begin{array}{l}\text { (Re) apresentações cartográficas do } \\
\text { espaço municipal mapas artísticos em } \\
\text { deriva da cartografia escolar. }\end{array}$ & Revista Geografares \\
\hline Claro e Pereira (2015) & $\begin{array}{l}\text { A postura fenomenológica enquanto } \\
\text { contributo à pesquisa em educação. }\end{array}$ & $\begin{array}{l}\text { Revista Sul-Americana de } \\
\text { Filosofia e Educação }\end{array}$ \\
\hline
\end{tabular}

Fonte: Elaborado pelas autoras (2020) 


\section{RESULTADOS}

\subsection{A Perspectiva da Geografia Fenomenológica}

O pensamento fenomenológico tem uma história relativamente bem definida, como demonstra a literatura da área, datada no início do século XX (com alguns indícios no século XIX), conforme nos esclarecem, Claro e Pereira, (2015, p. 25). Os estudos fenomenológicos evoluíram a partir da metade do século XIX com diversas contribuições. Logo, interroga-se o que é a fenomenologia e qual significado enquanto método fenomenológico para a ciência filosófica da época, ou seja, quais as possíveis contribuições e arguições para tal fundamento o explica enquanto método de conhecimento? Na perspectiva histórica, assinala Bertin (2013, p.106) que "a fenomenologia tem o seu significado contemporâneo atribuído à filosofia do alemão Edmund Husserl (1859-1938)". Com sua reflexão considerado o criador da fenomenologia moderna, ela nasce com a "crise do positivismo" que era a crença do saber absoluto, no ponto de vista da fenomenologia.

A fenomenologia de Husserl surge como uma reação original a de dominação intelectual, no campo da ciência, do naturalismo empírico, do pragmatismo, do objetivismo cientificista do positivismo, da ciência mecanicista e excessivamente quantitativa. Acrescenta Claro e Pereira (2015, p. 99) que este movimento filosófico da fenomenologia era baseado na "subjetividade sob a perspectiva husserliana, a qual ganha um sentido diferente do que a razão cartesiana preconizava". A fenomenologia definida por este autor nos diz que é a ciência que estuda o fenômeno, aqui entendido como fenômenos físicos. Completa Husserl (2002, p.11) que: “por fenômeno, no sentido originário e mais amplo, entende-se tudo o que aparece, que se manifesta ou se revela".

Desta forma, pode-se concluir que o fenômeno ao qual Husserl atribui é a capacidade de ter consciência, ou seja, um método de conhecimento que será o estudo dos fenômenos puros como os mesmos se mostram. Sendo assim, Husserl (2002, p.12) sugere a "volta às coisas mesmas", interessando-se pelo puro fenômeno 
tal como se torna presente e se mostra à consciência. Contudo, uma indagação surge a respeito do que de fato significaria a "consciência"? Para o alemão, seria: “a) consciência como conjunto de todas as vivências, ou seja, a consciência como unidade; b) a consciência como percepção interna das vivências psíquicas, ou seja, o ser consciente; c) a consciência como vivência intencional" (HUSSERL, 2002, p. 21).

Portanto, pode-se analisar que o método fenomenológico “não se preocupa em ser exato, mas antes, se ocupa dos fenômenos vividos da consciência a partir de um conceito que é fundamental nesta tentativa de relançar a temática da percepção - a consciência intencional" (ALMEIDA, 2011, p. 47). Considerando este movimento filosófico encaminhando para o mundo interior o transcendental aqui compreendido como o que é irreal. Porém, logo vem, a saber, o que seria transcendental? Para Claro e Pereira (2015, p.100): “Fenomenologia Transcendental é a ciência da essência do conhecimento”.

O criador deste método ainda expõe que a "fenomenologia pretende ser ciência das essências e não dos fatos. É ciência de experiência, que descreve os universais que a consciência intui quando se lhe apresentam os fenômenos" (HUSSERL, 2002, p.14). Ainda completam os autores, Claro e Pereira (2015), que a fenomenologia é o caminho, um método que tem por finalidade a constituição da ciência e da essência do conhecimento.

Portanto, a fenomenologia é um método no qual a intencionalidade da consciência leva em prevalência a percepção das experiências vividas, assim, o que importa é o que sujeito pensa sobre o objeto, conforme permite o humanismo para a ciência filosófica. Como também, em outras palavras, a intencionalidade para Husserl é uma relação entre o fenômeno e a vivência (ALMEIDA, 2011, p.53).

Nesse ponto de vista, o ensinamento de Husserl a partir do conceito de intencionalidade, Almeida (2011, p. 47) salienta que: “princípio da intencionalidade é que a consciência é sempre consciência de alguma coisa". Claro e Pereira (2015, p.102) que defendem a ideia de que o "pensar", a consciência não é pura, asseguram para este movimento filosófico que a consciência é, portanto, intencional.

Do mesmo modo, Claro e Pereira (2015) enfatizam que é preciso abrir-se às manifestações do fenômeno (do mundo vivido, enfim, do objeto ou sujeito de 
estudo), como também se torna importante atentar para a presença da intencionalidade no pensamento de Husserl. Com isso, a intencionalidade chega-se, segundo Claro e Almeida (2015, p.104), a redução fenomenológica, assumindo valores e sentidos originais sem conceitos pré-concebidos.

Assim, Bertin (2013, p.108) considera que "a fenomenologia busca estudar as essências" e que seria identificar esta essência das coisas por meio de reduções fenomenológicas, do movimento de trazer algo à superfície pelo plano natural e não o conhecimento do plano lógico, ou seja, considerando a percepção e a consciência. Como também compreendem Claro e Pereira (2015, p.104) que a "redução fenomenológica enquanto possibilidade de acesso ao retorno da consciência".

Bertin (2013, p. 106) ainda traz outra contribuição dizendo que, para o francês Maurice Merleau-Ponty, além de expandir as teorias de Husserl, propõe uma filosofia "fenomenológica da percepção". Neste momento, Almeida (2011, p.48) destaca que a teoria do filósofo francês Ponty pode ser definida como uma "filosofia transcendental, a fenomenologia coloca o mundo vivido a priori das reflexões e justifica, por isso, o esforço em compreender o homem e o seu mundo a partir da facticidade". Entretanto, observa-se na contribuição de Merleau-Ponty, a fenomenologia da percepção com o aporte, o qual traz pontos chave sobre a percepção, ou seja, é uma relação do nosso corpo com o objeto, mundo vivido e o mesmo é uma experiência contida de significação, história de vida de cada sujeito de acordo com a sua vivência social e de afetividade, desejos e paixões, isto é, subjetivação.

Assim, a percepção é uma forma organizada e estruturada que captamos através dos nossos sentidos (visão, audição, paladar, olfato e tato) sem receber estímulos do nosso cérebro e esta percepção está sujeita de forma dualista. Logo, a contribuição da fenomenologia que Maurice Merleau-Ponty trouxe para o pensamento geográfico foi o mundo interior, o corpo e exterior dos objetos, e mostrou que o ser humano vê o mundo e os fenômenos conforme a sua cultura, religião, educação, sentimentos e meio ambiente, mas também, a importância desta concepção da área do conhecimento presencia-se na corrente da Geografia humanista. 
Sendo assim, a fenomenologia e suas análises através do conceito de lugar-mundovivido, de intencionalidade e de intersubjetividade são necessários para a construção das noções de espaço e lugar. Como afirma Almeida (2011), mencionando que este pensamento abriu novas possibilidades para o pensamento geográfico acerca da compreensão da sociedade atual, no sentido de encontrar respostas para a construção de valores.

Segundo Bertin (2013, p.107), "foi Edward Relph o primeiro geógrafo, cujo interesse pela fenomenologia de Husserl assinala o intuito de buscar um suporte filosófico para uma possível aproximação Humanista com a ciência geográfica". Neste contexto, Bertin (2013, p.109) deixa claro que "pode-se afirmar então que o método fenomenológico se aplica a várias interfaces natureza x sociedade, buscando explicar como se opera a consciência das coisas". Já Almeida (2011) escreve que a fenomenologia proporciona como contribuição às pesquisas sobre o homem, sobre sua consciência, e sobre suas relações com o espaço e o lugar.

Nesse sentido, a base filosófica da Geografia humanista para Bertin (2013, p.107) foi apropriada desses “(...) postulados filosóficos de ideais provenientes da fenomenologia, do existencialismo, com pinceladas idealistas e da hermenêutica (interpretativa), que interessavam mais diretamente à Geografia". Para o pensamento da Geografia humanista, o conceito de Husserl sobre a intersubjetividade vai ao encontro "da ideia de "herança sócio-cultural" e do "papel de cada um no mundo vivido". (ALMEIDA, 2011, p.54).

A subjetividade está na pauta do humanismo, como traz o enfoque fenomenológico. Este resgata o mundo vivido como escala e categoria de análise, permitindo a compreensão mais orgânica da relação homem-meio, através do conceito de lugar e o estudo da memória, dos símbolos e da identidade. Estes tornaram esta relação mais viva e humana. (MARANDOLA, 2005, p.409)

O autor Marandola (2005) disserta que a Geografia humanista tem como "inaugurador" o geógrafo chinês Yi-Fu Tuan que trabalha na perspectiva da heterogeneidade, sendo que este método de análise geográfica, valoriza o conhecimento a partir das percepções, representações. 
Enfatiza Paula (2014) que no Brasil a Geografia humanista apareceu nas décadas de 1970 e 1980, a partir das pesquisas sobre percepção ambiental, desenvolvidas pela geógrafa Lívia de Oliveira. A referida geógrafa também traduziu os livros de Yi-Fu Tuan. A partir daí, surgiram espaços e diálogos de discussões do humanismo no Brasil.

Deste modo, pode-se destacar a importância do autor Yi-Fu Tuan com suas pesquisas principalmente com a sua obra "Espaço e Lugar" que apresenta a perspectiva experiencial, o viés da análise do subjetivismo para a geografia humanista, pois ressalta a importância das pessoas depreenderem o espaço e lugar dos diversos modos de vivenciar, ou seja, através dos órgãos dos sentidos (o olfato, paladar e tato) e a percepção (visão) para conceberem o espaço e lugar a partir da capacidade para a criação de símbolos.

Segundo Yi-Fu Tuan, destaca-se que as produções sociais e culturais mostram a sensação de espaço e lugar a partir de diferentes experiências, melhor dizendo, os lugares em que o homem vive que são compostos de vários significados. Pois a fenomenologia na análise do espaço pela percepção do mundo vivido é uma experiência contida de significação, história de vida de cada sujeito de acordo com a sua vivência social e de afetividade, desejos e paixões, isto é, subjetivação.

Portanto, levando em conta as inter-relações existentes que a fenomenologia traz para a Geografia é possível trabalhar e discutir as conexões da paisagem e lugar por meio perceptivo e experiencial do âmbito da Geografia humanista. Assim, a Geografia das singularidades são representações de relações sociais, capazes de mostrar as produções de identidades culturais.

Logo, para realizar-se a leitura da paisagem e lugar a partir de leituras sociais do vivido, percebido e concebido, sem dúvidas, são atribuídos diversos sentimentos e valores que só se conseguem pela compreensão da Geografia humanista, a qual trouxe ao agregar a fenomenologia da percepção e a semiótica que examina a produção de significação. Nesse sentido, a percepção da paisagem e lugar versa das relações de vivências humanas sobre elos e sentimentos com o lugar, expressos através de representações sociais, os quais serão apresentados a seguir. 


\subsection{A Percepção da Paisagem e Lugar}

De acordo com Oliveira (2000), na antiguidade clássica, a Geografia tinha por propósito o estudo da paisagem, e isto envolvia em basicamente localizar e descrever os lugares na superfície da Terra. A categoria de análise da paisagem para Geografia, como se observa, sempre esteve vinculada à ideia de formas visíveis da simples descrição, mas ressalva Oliveira (2000, p. 17) que "nossa tarefa é tentar ultrapassar a paisagem como aspecto visual para chegar ao seu significado e valor", e para isso acontecer, deve-se levar em conta a importância dos estudos de percepção da paisagem que vai ao encontro do pensamento de Maurice Merleau-Ponty da fenomenologia da percepção que designa pela união subjetiva e experiencial na busca da essência.

Assim sendo, a partir da segunda metade do século XX, ocorreram, segundo Bertin (2013, p.112) os "estudos da percepção do ambiente e como isso afeta a vida da sociedade". Deste modo, "a percepção humana, por sua vez, está envolta de fatores intrínsecos de cada indivíduo, tomando os seus sentidos como a porta de entrada do processo perceptivo" (BERTIN, 2013, p.113).

De acordo, com Oliveira (2000, p. 17), “o estudo de percepção de paisagens tem sido realizado no campo da percepção do meio ambiente" através da perspectiva experiencial humana de Yi-Fu Tuan. Segundo Tuan (2013,p.13): "os órgãos sensoriais e experiências que permitem aos seres humanos ter sentimentos intensos pelo espaço e pela qualidade espaciais são a cinestesia, visão e tato". De forma que a percepção da paisagem na vertente aqui explanada em conformidade com os estudos de Tuan $(2013$, p.11) destaca que "a experiência é constituída de sentimento e pensamento" e nossas percepções são nossas experiências com o fenômeno, ocorrendo de maneiras e situações distintas uma vez que estão atreladas às vivências no espaço de cada corpo no mundo.

Experiência é um termo que abrange as diferentes maneiras através das quais uma pessoa conhece e constrói a realidade. Esta maneira varia desde os sentidos mais diretos e passivos como o olfato, paladar e tato, até a percepção visual ativa e a maneira indireta de simbolização. (TUAN, 2013, p.9) 
Nesse sentido, pensar a paisagem no viés da abordagem da Geografia humanista e com base na filosofia, o método fenomenológico é, segundo Oliveira (2000, p.19), um "espaço subjetivo, sentido e vivido, um espaço de cada ser humano, um espaço individualizado". Neste enfoque consegue-se movimentar para o estudo das paisagens cotidianas na organização espacial de um lugar a partir de análises sociais. Para tanto, “(...) a paisagem se define como um espaço percebido. Essa percepção se distingue das construções e símbolos elaborados a partir dela e exige método de análise" (OLIVEIRA, 2000, p.19). A paisagem percebida é, portanto, segundo a autora, construída e simbólica, como também é tudo o que se vê de um lugar, ou seja, depende de um ponto de vista, e de unidade ou conjunto. Assim, enfatiza Oliveira (2000, p. 19) no entendimento de paisagem perceptiva o seguinte pensamento:

(...) as ligações do homem com a paisagem envolvem três grupos de variáveis: paisagem, pessoas e interação. O contexto de interação entre o homem e a paisagem depende de seu humor e de suas circunstâncias, da iluminação e hora do dia, de se a paisagem é vista de um veículo ou a pé, de escolhas deliberadas ou de visitas acidentais de campo. Os propósitos do observados contribuem significativamente na determinação de suas preferências por lugares.

Na percepção da paisagem relaciona-se como corpo, ou seja, a apreensão dos sentidos, tratando-se de uma expressão sociocultural criadora, a partir das distintas lentes sobre o mundo, como ponderou Yi-Fu Tuan em suas contribuições para a Geografia na busca das essências. E essência da paisagem está em um conjunto de formação de signos, que envolve leituras subjetivas realizadas por pessoas que as atribuem valores, crenças, sentimentos, imaginação, familiaridade e vida cotidiana. Esses fenômenos podem ser captados por representações cartográficas sociais porque as mesmas são leitura da paisagem instituída em espaços sociais que permitem interpretar como são compostas tais paisagens.

Então, fica evidente que neste movimentar da ação e intervenção social refletindo os fenômenos geográficos apresentam a percepção da paisagem, como 
também criadora de identidades impregnada de imagens, criatividade, generalizada de simbolismo, de representações sociais e expressões culturais.

De forma que a paisagem cultural, que são interações afetivas entre o indivíduo e a natureza, e emergindo como um lugar simbólico de dada cultura e temporal, a paisagem enquanto dinâmica espacial revela aspectos visíveis por formas e funções o que está à vista dos olhos e se fixam em alguns pontos (monumentos, casas, ruas, etc...), e invisível o que está na mente humana (paisagens sonoras) e consequentemente da união da paisagem com a sociedade.

A autora Paula (2015, p. 233) destaca a importância do geógrafo Augustin Berque que trabalha a perspectiva fenomenológica com o seu artigo "Paisagem-Marca, Paisagem-Matriz: elementos da problemática para uma Geografia Cultural", em outras palavras, significa que a marca retrata um povo, todavia também é matriz porque são concepções, percepções culturais. Berque acrescenta, segundo Paula (2015, p.234), que o “(...) devir histórico e cultural que nos leva a adensar as estruturas de significados e sentidos dos objetos, ou seja, como a intencionalidade humana se desenvolve".

Como diz Tuan (2013), a percepção do espaço pelo homem depende da qualidade de seus sentidos e também de sua mentalidade, da capacidade da mente de extrapolar além dos dados percebidos e, essencialmente, da cognição. Esta percepção do espaço e lugar analisados por Tuan são experiências comuns e a diferença entre o espaço (mais abstratos) e o lugar (sendo o concreto) são abastecidos de experiências e significados íntimos (como carinho, lar, aconchego, lazer, alimento) possuidor de simbolização.

Para tanto, Tuan compreende que o lugar é singular e experiencial através da nossa percepção. O estudo do lugar para Gonçalves (2007, p. 525) é “matéria prima da geografia, que vê a consciência do lugar como uma parte imediatamente aparente da realidade e o seu conhecimento como "um simples fato da experiência". Assim, a percepção do lugar se dá pelos sentidos, mas também, para Ponty (1999, p. 63), perceber o lugar “(...) não é julgar, é aprender um sentido imanente ao sensível antes de qualquer juízo". Conforme Relph, o lugar é um modo particular de relacionar 
experiências de espaço na vida cotidiana, podendo ser identificado a partir de três elementos que se interagem: traços físicos, atividades e funções observáveis e significados ou símbolos.

Os geógrafos fenomenologistas, como os da escola do espaço vivido, procuram revalorizar o conceito clássico de lugar. Este conceito toma no discurso humanista a forma de um ponto no espaço onde todas as significações culturais e individuais se concentram. (GOMES, 2000, p.329)

Dessa maneira, o conceito de mundo vivido seria o lugar onde as coisas articulam nossos movimentos e ações, entretanto, cabe esclarecer que o conceito de lugar não é visto apenas como localização referencial, mas como o fenômeno experiência dos e pelos homens que nele vivem. Lima e Kozel (2009, p. 211) compactuam com essa conceituação de mundo vivido quando observam que "o lugar é vivido a partir das experiências individuais e coletivas com os que partilham os mesmos signos e símbolos".

Todos os lugares são pequenos mundos: o sentido do mundo, no entanto, pode ser encontrado explicitamente na arte mais do que na rede intangível das relações humanas. Lugares podem ser símbolos públicos ou campos de preocupação (fieldsofcare), mas o poder dos símbolos para criar lugares depende, em última análise, das emoções humanas que vibram nos campos de preocupação. (TUAN, 2013, p. 421)

O método fenomenológico considera basicamente os conceitos de mundo vivido que na Geografia seria identificado com o conceito de "lugar". Desse modo, utilizar-se do conceito de "lugar" apontaria para um método de descrever o mundo cotidiano da experiência do homem, abrangendo suas ações, lembranças, fantasias e percepções.

A partir do que fora até aqui elucidado, nota-se com vigor a significância sobre os respectivos apontamentos da análise da paisagem e lugar na perspectiva da geografia fenomenológica. Assim, a percepção se refere à experiência através da corporeidade, basicamente tendo enfoque nas singularidades como campo do conhecimento das relações cotidianas, culturais, do diálogo, amor, contradição e afetividades. A relevância para trabalhar os processos perceptivos também irá 
apresentar a Geografia da vida, onde as coisas acontecem e emergem, com as leituras subjetivas e estéticas da paisagem, como expressão de habitar no mundo, com isso, tornando cada ser humano produtor do desvendamento do seu cotidiano bem como efetivando o papel da geografia no mundo.

E, para compreender as paisagens a partir das percepções, isto é, a partir de um conjunto composto por sentimentos, experiências, essências e valores culturais, abordados pelo domínio da Geografia humanista pela natureza fenomenológica, isto (o entendimento) se dá a partir de averiguações de leituras cartográficas sociais como os mapas mentais - como já mencionado. Estes são entendidos como mecanismos para melhor expressar as percepções, concepções e vivências de mundo individualizado que ao expor para outrem torna um conhecimento coletivo sobre a organização do espaço.

Para tanto, ao se utilizar de representações cartográficas, como investigações de como as pessoas percebem os ambientes com o qual vivem e são capazes de desvendar as particularidades, é o que será abordado a seguir, partindo sempre da importância dessas representações como forma de captações sociais para o ensino de Geografia.

\subsection{Elaborações de mapas mentais no ensino de Geografia}

Na perspectiva de análise da paisagem e do lugar, têm-se as contribuições das representações cartográficas a partir dos mapas mentais. Richter (2010) ressalta que os mapas mentais têm sua origem na área da Psicologia através de David Lowenthal, autor este que discorre sobre Geografias Pessoais. Paula (2014, p. 231) destaca que os "estudos dos mapas mentais de origem anglófona, ligados à psicologia, busca entender o comportamento espacial dos indivíduos a partir da percepção e memorização do ambiente". Já Kevin Lynch (1999) na sua abordagem acerca de o estudo da percepção ambiental, com seu livro "A Imagem da cidade", disserta sobre o estudo das representações espaciais (como legibilidade), que são representações cartográficas elaboradas através das percepções individuais ou coletivas. 
Nesse sentido, cartografias da singularidade abrangem a habilidade de cartografar elementos do espaço a partir de suas experiências que trazem, além das formas da paisagem percebida, a relação com sua história de vida ao passo que existe relação entre o psíquico mental que é o percebido e formando imagem mental e posterior a representação. Tanto que "a imagem como representação do espaço é utilizada desde a pré-história, com o aparecimento da linguagem simbólica, quando o homem gravou na pedra as cenas do seu cotidiano, da sua história, das direções percorridas" conforme esclarecem (LIMA e KOZEL, 2009, p.211).

Assim, a interpretação da paisagem vivida atenta sobre o fato de que "os mapas mentais são representações do vivido, são os mapas que trocamos ao longo de nossa história com os lugares experienciados" (ARCHELA, GRATAO e TROSTDORF, 2004, p.127). Como também destacado pelos autores supracitados, a importância do conhecimento geográfico pode ser representada através de mapas mentais, estes que desvendam a paisagem vivida em um determinado tempo histórico. Os mapas mentais nada mais são do que desenhos, representações do espaço espontâneos pelo meio das contemplações sensíveis, das diferentes experiências do espaço, portanto, pode-se dizer que são representações dos saberes percebidos, simbólicos, subjetivos e imateriais.

Dessa maneira, a cartografia humanista cultural não cartesiana com enfoque fenomenológico, em que o uso da linguagem é forma de expressão das experiências humanas, mostra que a percepção da paisagem acontece de formas diferentes entre os seres humanos, pois cada pessoa apresenta certa percepção com relação tanto para com o espaço como para sua experiência de vida e é percebida através dos sentidos que o geógrafo Yi-Fu Tuan apresenta em suas pesquisas. O mundo de que se fala, percebido pelo meio da apreensão dos significados, provoca a construção mental na qual a racionalidade não lê essas imagens. Sobre isso, retoma-se as palavras dos pesquisadores Pereira e Seemann (2014): 
Constatando que cada pessoa tem uma percepção diferente da paisagem, por ter em suas entranhas um enredo sociocultural, político-econômico e imaginativo, torna-se imprescindível produzir métodos e ações para perceber a visão que o aluno tem sobre a paisagem. (PEREIRA e SEEMANN, 2014, p.2014)

No que diz respeito à representação cartográfica qualitativa de fenômenos geográficos na escola, aponta-se para a valorização do saber que o sujeito traz consigo para este ambiente, para esta cartografia não preocupada com a precisão e as características formais. Pois, na maioria das vezes, aparece no ensino da cartografia formal sem levar em conta os valores, sentimentos e vivência para percepção dos fenômenos no espaço. Com isto, as representações sociais expostas por meio dos mapas mentais na escola destacam para subverter no ensino o estudo do cotidiano, através do estudo dos signos que são formas de linguagem não verbais. Os mesmos constituem os símbolos, paisagem, cultura, pois quando um aluno analisa uma paisagem trará com ele seu lugar no mundo, ou seja, tudo aquilo que o compõem enquanto ser transcendental no espaço.

Logo, ressalta-se mais uma vez a importância da enfática elaboração desta revisão bibliográfica, apoiando-se em autores que assinalam para a análise do fenômeno a ser perceptivo para o ensino de Geografia a partir dos estudos fenomenológicos, destacando-se, por sua vez, o estudo da apropriação de conceitos geográficos, através das representações de Geografia, por alunos do ensino fundamental a partir de suas experiências.

(...) a fenomenologia permite estabelecermos uma conexão com os mapas mentais: ciência da experiência que analisa o fato sob a luz da percepção; mapas mentais que são produtos da imagem percebida, do registro perceptual do sujeito; os dois se complementam e se juntam para essa análise. (LIMA E KOZEL, 2009, p.211)

Dessa maneira, a vinculação da fenomenologia com o uso do mapa mental enquanto linguagem e ferramenta, torna-se capaz de integrar a cartografia escolar nas atividades didático-pedagógicas, no ensino de Geografia e isto tende a aparecer como uma demanda justificável e necessária que a escola precisa dar conta. Os autores Pereira e Seemann (2014, p.53), salientam que “o ato de mapear é muito mais 
que uma mera reprodução inconsciente, que representa o espaço configurado da forma que é apresentado". A escola necessita deste movimento de que apreender a cartografar escolar como métodos subversivos e imaterial, complexos plurais e imaginativos, isto é, uma linguagem a não verbal que são os símbolos, gestos, imagens, representação por atos de percepção que é algo que pode "(re)pensar o espaço, (re)apresentando-o com suas novas configurações e dimensões", afirma (PEREIRA, e SEEMANN, 2014, p.53).

Os mapas mentais no processo de ensino-aprendizagem de Geografia têm possibilidades de elementos subjetivos, estas que os mapas tradicionais não podem dar conta, por exemplo, por apresentarem um caráter objetivo. Então, a articulação com as categorias de análise espacial, paisagem e lugar, por meio da produção de mapas mentais no ensino de Geografia, nos permite a leitura e análise dos fenômenos geográficos.

O mapa mental permite observar se o aluno tem a percepção efetiva da ocorrência do fenômeno no espaço e condições de transpor essa informação para o papel. Através dessa atividade, ele trabalha com todos os elementos essenciais da cartografia quanto a sua forma de expressão, através da linguagem gráfica. (ARCHELA, GRATAO e TROSTDORF 2004, p.140).

Archela, Gratão e Trostdorf (2004, p.129) definem que para a interpretação de mapas mentais se deve instituir critérios como “(...), por exemplo, faixa etária, diferenças sociais, herança biológica, cultural e educação, pois estes elementos constroem diferentes percepções do espaço".

A análise da paisagem com a construção dos mapas mentais na perspectiva da leitura da escala espacial e de representação, acontece quando os alunos reconhecem os elementos sociais, culturais e naturais e a interação existente, o que acarreta em um aprendizado de forma mais dinâmica sobre a representação da paisagem. Conforme respalda Pereira e Seemann (2014), os alunos desvendam todas as paisagens que vivenciam em seus trajetos nos seus mapas mentais e isso liberta de forma espontânea a Geografia singular. 
Sendo assim, para se construir o modo como acontece a percepção da paisagem na escola com a contribuição das representações sociais, fez-se a leitura dos artigos e levantamento conceitual sobre elaborações de mapas mentais no ensino de Geografia e sua importância, em que foi possível constatar diferenças e, principalmente, confluências na representação do espaço entre os autores que encaminham várias questões, permitindo o estudo dos mapas mentais por diversos pensamentos, como aponta o quadro 2.

Quadro 2- Estudos cultural e humanístico.

\begin{tabular}{|l|l|l|l|}
\hline AUTOR & TíTULO & ANO & MÉTODo DE ANÁLISE \\
\hline $\begin{array}{l}\text { ARCHELA, Rosely Sampaio, } \\
\text { GRATÃO Lucia Helena N. } \\
\text { Gratão. TROSTDORF, Maria } \\
\text { A. S. }\end{array}$ & $\begin{array}{l}\text { O lugar dos mapas mentais na } \\
\text { representação do lugar. }\end{array}$ & 2004 & $\begin{array}{l}\text { Psicologia, Cartografia e } \\
\text { Geografia. }\end{array}$ \\
\hline $\begin{array}{l}\text { LIMA, Angélica Macedo } \\
\text { Lozano, KOZEL, Salete }\end{array}$ & $\begin{array}{l}\text { Lugar e mapa mental: uma } \\
\text { análise possível. }\end{array}$ & 2009 & $\begin{array}{l}\text { Método da geografia } \\
\text { humanista cultural com } \\
\text { aporte fenomenológico. }\end{array}$ \\
\hline $\begin{array}{l}\text { PEREIRA, Cássio Expedito } \\
\text { Galdino, SEEMANN, Jorn. }\end{array}$ & $\begin{array}{l}\text { (Re) apresentações cartográficas } \\
\text { do espaço municipal mapas } \\
\text { artísticos em deriva da } \\
\text { cartografia escolar. }\end{array}$ & 2014 & $\begin{array}{l}\text { Geografia artística, } \\
\text { pessoal e cultural. }\end{array}$ \\
\hline BERTIN, Marta. & $\begin{array}{l}\text { Geografia Humanística- O papel } \\
\text { das Representações Sociais e } \\
\text { Espaciais em Manifestações } \\
\text { Contemporâneas. }\end{array}$ & 2013 & $\begin{array}{l}\text { Geografia humanista } \\
\text { cultural com aporte } \\
\text { fenomenológico. }\end{array}$ \\
\hline
\end{tabular}

Fonte: Elaborado pelas autoras (2017)

Quanto à concepção de mapas mentais na produção de artigos acerca da educação geográfica, observam-se três tendências: a) a primeira concepção que diz respeito à questão identificada nos estudos foi de que o "mapa mental é um instrumento didático". Neste artigo, os autores Archela, Gratão e Trostdorf (2004) ressaltam os mapas mentais utilizados como recurso didático e pedagógico e o estudo de conteúdos do ensino fundamental; em seguida, dão destaque para o planejamento do trabalho docente, já que este é eficaz em sua capacidade de alcançar os objetivos em seu uso. Já os autores Pereira e Seemann (2014) destacam a discussão do uso do mapa mental com base em 
estudo de caso em escolas públicas, mostrando a importância deste instrumento didático ao considerar que são capazes de desvendar a Geografia que existe no nosso cotidiano e que não aparece em livros didáticos, esta realidade de espaços onde os alunos estão inclusos fundamentalmente.

Em suma, os dois artigos em questão explanam o refinamento diversificado e a possibilidade de formação dessa ciência aos interessados em pesquisar o objeto de análise da Geografia que é, se não, o espaço geográfico. Assim, os mesmos autores elencados acima abordam a cartografia no ensino de Geografia voltada para a realidade escolar através do uso do mapa mental, enquanto ferramenta em uma abordagem capaz e verossímil de conduzir melhor a apreensão da realidade.

Archela, Gratão e Trostdorf (2004) trazem a questão de os mapas mentais como um ensaio metodológico pelo viés da representação do lugar bem como sua importância a partir do ponto de vista da Geografia humanista, apresentando o conceito de lugar como movimento indispensável para o entendimento da Geografia e sua forma de manifestar as representações da vida cotidiana, sentimentos e valores do ser humano na sociedade.

Quadro 3 - Mapa mental é um instrumento didático.

\begin{tabular}{|l|l|}
\hline \multicolumn{2}{|l|}{ Mapa mental é um instrumento didático } \\
\hline AUTOR & TENDÊNCIAS \\
\hline $\begin{array}{l}\text { ARCHELA, Rosely Sampaio, GRATÃO, } \\
\text { Lucia Helena N. TROSTDORF, Maria A. S. }\end{array}$ & $\begin{array}{l}\text { Mapa mental possa ser utilizado como um recurso } \\
\text { didático e pedagógico para o estudo de conteúdos } \\
\text { do ensino fundamental. }\end{array}$ \\
\hline $\begin{array}{l}\text { PEREIRA, Cássio Expedito Galdino, } \\
\text { SEEMANN, Jorn. }\end{array}$ & Mapa mental utilizado no ensino de geografia. \\
\hline
\end{tabular}

Fonte: Elaborado pelas autoras (2017)

Neste contexto, a discussão dos mapas mentais como instrumento didáticopedagógico no ensino de Geografia foi movimentada pelas orientações contidas em instrumentos norteadores da educação que recomendam a ótica cultural e humanista 
para os anos finais do ensino básico. Em vista disto, o aluno será capaz de entender melhor a sua realidade, ajudando a construir o mundo e transformando-se em um agente ativo do processo de aprendizagem, como apresentado no quadro 3 as tendências dos autores.

Já o quadro 4, exposto a seguir, apresenta a análise do item b) a segunda concepção: "Mapa mental exerce uma função de análise do espaço produzido pelo estudante", de acordo com as autoras Archela, Gratão e Trostdorf (2004). Estas realizaram um ensaio de representação de um lugar, relatando o quão foi relevante as "impressões e relações de vivência com a cidade" produzidas por crianças e adolescentes. No seu caminho metodológico, tais autoras propuseram-se a avaliar os mapas mentais produzidos por estudantes como a leitura e revelações pelo indivíduo e a interpretação dos pesquisadores.

Quadro 4 - Mapa Mental exerce uma função de análise do espaço.

Mapa mental exerce uma função de análise do espaço produzido pelo estudante

\begin{tabular}{|l|l|}
\hline AUTOR & TENDÊNCIAS \\
\hline $\begin{array}{l}\text { ARCHELA, Rosely Sampaio, } \\
\text { GRATÃO Lucia Helena N. } \\
\text { Gratão. TROSTDORF, Maria A. } \\
\text { S. }\end{array}$ & Mapas mentais são imagens espaciais que as pessoas têm de lugares \\
\hline $\begin{array}{l}\text { LIMA, Angélica Macedo } \\
\text { Lozano, KOZEL, Salete. }\end{array}$ & $\begin{array}{l}\text { Os mapas mentais formam uma análise a respeito de um lugar visto } \\
\text { através dos olhares dos próprios moradores e da sua vivência. } \\
\text { Apontam um caminho para diversas interpretações e ao mesmo } \\
\text { tempo, proporcionam uma observação sensível do lugar que está } \\
\text { impregnado de elementos subjetivos presentes no seu cotidiano. }\end{array}$ \\
\hline $\begin{array}{l}\text { PEREIRA, Cássio Expedito } \\
\text { Galdino, SEEMANN, Jorn. }\end{array}$ & $\begin{array}{l}\text { Os mapas produzidos tornaram-se um meio para analisar a } \\
\text { percepção dos elementos paisagísticos percebidos pelos alunos, } \\
\text { levando a um melhor entendimento de como está a paisagem e quais } \\
\text { são seus possíveis problemas. }\end{array}$ \\
\hline
\end{tabular}

Fonte: Elaborado pelas autoras (2017)

Assim sendo, os mapas mentais enquanto análise do espaço com elementos fundamentais, elementos produzidos pelo homem de uma cidade e a movimentação do lugar, mostram o tipo de relação experiencial que o estudante tem com o lugar, por sua vez, estabelecendo uma relação de afetividade (felicidade e alegria) ou 
mesmo expressar um sentimento de angústia, medo, raiva, dor, tristeza. Através destas representações informais os estudantes conseguem transpor para o papel a sua cultura e seus diferentes sentimentos em formas de ícones, símbolos e signos, comunicando de toda forma sua consciência enquanto ser atuante e social.

As autoras Lima e Kozel (2009, p. 226) realizaram suas análises de mapas mentais com moradores a partir de observações de um bairro. Para elas, "estas representações marcam um espaço sociocultural, permeado por valores subjetivos, como a condição de classe social, dos limites, subjetivamente representado nos mapas". Pereira e Seemann (2014, p.54), por sua vez, procuram a produção dos mapas mentais realizados por alunos e professores, pois segundo os pesquisadores, os “(...) mapas não devem ser compreendidos como artefatos prontos e acabados, mas como processos de indagação para o ensino".

Por conseguinte, a terceira concepção desenvolvida neste estudo abrange o ponto comum entre os autores presentes no quadro 5, item c) "Mapas mentais são representações do espaço vivido do cotidiano". Neste item, observa-se que as cartografias culturais são reveladas e desvendadas pelo seu criador, no caso do estudo os estudantes; fazer aparecer algo novo no espaço a partir dos seus saberes e realidade da experiência cotidiana.

Quadro 5- Mapas Mentais são representações do espaço vivido do cotidiano.

\section{Mapas mentais são representações do espaço vivido do cotidiano}

\begin{tabular}{|l|l|}
\hline AUTOR & TENDÊNCIAS \\
\hline $\begin{array}{l}\text { ARCHELA, Rosely Sampaio, } \\
\text { GRATÃO Lucia Helena N. Gratão. } \\
\text { TROSTDORF, Maria A. S. }\end{array}$ & $\begin{array}{l}\text { As representações espaciais mentais podem ser do espaço vivido } \\
\text { no cotidiano. }\end{array}$ \\
\hline $\begin{array}{l}\text { LIMA, Angélica Macedo Lozano, } \\
\text { KOZEL, Salete. }\end{array}$ & $\begin{array}{l}\text { Revelam intenções, ações e o cotidiano das pessoas de um lugar } \\
\text { por meio dos desenhos, da sua análise e das vivências. }\end{array}$ \\
\hline $\begin{array}{l}\text { PEREIRA, Cássio Expedito Galdino, } \\
\text { SEEMANN, Jorn. }\end{array}$ & $\begin{array}{l}\text { A produção de mapas mentais voltados ao entendimento da } \\
\text { paisagem do espaço vivido feito pelos alunos e professores da } \\
\text { rede de ensino básico do município de Barbalha, Ceará, tornando } \\
\text { o processo de ensino-aprendizagem da escola mais dinâmico e } \\
\text { proveitoso. }\end{array}$ \\
\hline
\end{tabular}

Fonte: Elaborado pelas autoras (2017) 
Como pode ser observado no quadro 5, as representações do espaço vivido são mapas metais do cotidiano, sendo assim, os mesmos possuem informações espaciais de cada indivíduo e sua linguagem cultural em um instrumento de comunicação.

Os desenhos evidenciam a Geografia presente naquele espaço, mostram claramente como as crianças percebem o seu espaço vivido, seja por narrativas dos mais velhos, seja por atividades diárias que realizam ou manifestações culturais das quais estão participando. (PEREIRA e SEEMANN, 2014, p.55)

Neste momento, o raciocínio versa sobre a Geografia humanista do autor Yi-Fu Tuan em que o conceito de lugar é o espaço de experiências humanas e sob a análise de que o mapa mental ao ser usado por professores de geografia corrobora para uma melhor captação dos lugares, visto que as representações compreendem o lugar das experiências. Nesse ângulo, os autores respaldam que podem levar o "aluno a questionar as situações concretas que vivenciam em seu cotidiano, estimulando-os a procurar respostas para os problemas sociais" (ARCHELA, GRATÃO E TROSDORF, 2004, p.140).

Pereira e Seemann (2014) apresentam as representações cartográficas relacionadas à percepção da paisagem vivida pelo aluno. Os autores atentam para os Parâmetros Curriculares Nacionais, sobre algumas indagações: a primeira, acerca da importância de ler criticamente a paisagem e, em seguida, desenvolvem algumas indagações sobre como os professores trabalham a paisagem do cotidiano visto pelo aluno, por exemplo, "como podemos agir nos problemas que afligem este espaço vivido, sem entender de que espaço se trata?" (PEREIRA, e SEEMANN, 2014, p.140).

Assim sendo, com base nas representações dos mapas mentais, constata-se forte ligação com a Geografia cultural humanista que valoriza a subjetividade, os sentimentos, a experiência e as percepções dos sujeitos alunos acerca dos seus espaços vividos, enfoque este da fenomenologia. A Geografia consiste em uma ciência social e, ao ser analisada pela cartografia social e cultural, obriga-se a valorizar o aluno e a sociedade em que vive em um ser histórico. 
Seguindo esta lógica, pode-se considerar que compreensão sobre a Geografia escolar é aquela em que apercepção dos alunos por meio dos mapas mentais permite um maior conhecimento. Logo, entende-se que a utilização de mapas mentais é uma ferramenta metodológica, primordialmente com sua codificação e seguido da decodificação; um caminho de mudança vantajoso para os professores. Ou seja, é importante que os alunos sejam estimulados a partir de seu conhecimento empírico da percepção e representação aos conceitos geográficos.

A partir do exposto pelos textos e discussões dos autores torna-se evidente demonstrar que as contribuições do aporte da Geografia humanista e da Geografia das representações somam-se mais do que as análises descritivas do espaço. Assim, considerando os diferentes pontos de vista apresentados até aqui pelos pesquisadores da Geografia, apresentam subsídios para a Geografia escolar enquanto respaldaram-se em relacionar e apresentar os mapas mentais como alternativas para trabalhar o espaço percebido, concebido e vivido pelos alunos, mas também, indo além, através das suas representações sociais.

\section{DISCUSSÃO}

A partir do que foi explanado nos tópicos acima, em suma, pode-se dizer que a Geografia na abordagem fenomenológica do conhecimento valida que "a percepção é considerada originária e parte principal do conhecimento humano, mas com uma estrutura diferente do pensamento abstrato, que opera com idéias" (CHAUI, 2000, p. 156).

Pode-se destacar Yi-FuTuan como sendo um dos primeiros geógrafos a trabalhar nesta linha de pensamento humanista, logo, explica o aprendizado do espaço e lugar através da experiência, a qual provoca a capacidade de aprender a partir da própria vivência. Para Tuan (2013, p.10), "experenciar é aprender, significa atuar sobre o dado e criar a partir dele. O dado não pode ser conhecido em sua essência". O estudo da paisagem e lugar da experienciação e percepção como uma atividade mental de 
interação do indivíduo com o meio ambiente em que acontece pelo meio de mecanismos perceptivos e cognitivos.

Portanto, a fenomenologia na Geografia implica em perspectiva do espaço que considera a percepção do sujeito sobre o objeto. Assim sendo, o mundo vivido e a subjetividade acarretam na compreensão do espaço nos estudos geográficos, seja através da percepção ou como nas representações sociais, o que pode ser uma possibilidade de se trabalhar no ensino fundamental com os conceitos geográficos, dentre eles a paisagem e o lugar.

O pensamento fenomenológico analisa os fenômenos no espaço e as representações carregadas de tipos de signos, os quais são formas de linguagem presentes nos cotidianos do ser humano o qual, também, pode ser interpretado. Desta maneira, as representações na escola podem ser utilizadas como uma forma de comunicação, através da linguagem não verbal - apropriada como a leitura da paisagem e lugar, na Geografia manifestados por meio de símbolos. No âmbito escolar, os mapas mentais valorizam os signos oriundos de cada aluno, como sabemos, concebidos através de sua percepção como ambiente, pois cada um lê a paisagem e o lugar de forma a trazer um pouco de sua vivência e afetividade para o que se lê, interpreta e sente.

Em termos de apropriação das representações, as cartográficas são maneiras pelas quais se faz a apreensão de mundo, entretanto, são os mapas mentais que podem apresentar os conceitos de Geografia de paisagem e lugar, valorizando o ser humano que produz seus valores de vida pelas suas próprias singularidades. Neste sentido, o ensino de Geografia em consonância com a compreensão da paisagem apresenta a necessidade de uma metodologia que nos direcione no sentido da tomada espaço/pedagógico, como possibilidades de construção de conhecimento.

As principais metodologias utilizadas ao longo dos artigos até aqui estudados foram orientadas a partir de estudo de obras dos filósofos Husserl e Maurice Merleau-Ponty. Já no que concerne a Geografia humanista, destaca-se a metodologia focalizada nos estudos do geógrafo chinês Yi-Fu Tuan. Com base em tudo o que fora 
lido e discutido nestas linhas, conclui-se enfaticamente a importância da Geografia fenomenológica, voltada a partir dos conceitos dissertados brevemente neste texto, justifica-se para tanto que "o mundo vivido, o mundo construído, o mundo físico são todas partes do mundo humano, ser humano interagindo com o espaço" e, assim, a necessidade de não deixar nenhuma das modalidades da vida e do homem fora de sintonia, sem conexão umas com as outras, pois que tudo que existe extra e internamente é parte significativa e atuante de nossas representações (LIMA e KOZEL, 2009, p. 228).

Por fim, em relação às pesquisas em educação geográfica, Claro e Pereira (2015) ressaltam as contribuições da fenomenologia e afirmam que a reflexão acerca de algo é resultado da percepção realizada. Enfim, a Geografia humanista fenomenológica é realmente importante, pois, segundo Almeida (2011) destaca, nos métodos tradicionais e cartesianos pouco se aprende de conhecimento sobre o ser humano com o espaço vivido e com uma abordagem humanista pode-se ampliar o objeto de estudo, contemplando novos saberes sobre a sociedade.

\section{CONCLUSÃO}

A análise da paisagem e lugar na teoria do conhecimento da fenomenologia, isto é, a percepção e a representação são um aporte teórico-metodológico no ensino de Geografia, uma vez que levam em conta aspectos humanos subjetivos em práticas educativas. Para compreender os fenômenos geográficos humanos, principalmente aqueles relacionados com experiências individuais, as ciências tradicionais positivistas não dariam contam. Dito isto, mostra-se importante à perspectiva fenomenológica para o estudo da paisagem e lugar no ensino de Geografia. Como sabe-se, a área de produção de mapas mentais dá conta apresentando excelentes trabalhos que devem ser utilizados em sala de aula, como se observou ao longo do trabalho, ou seja, contribuindo enquanto instrumento de ensino aprendizagem, análise do espaço produzido pelo estudante e representações do espaço vivido do cotidiano. 
Perante as reflexões apresentadas pelos autores, ao demonstrar que os mapas mentais utilizados como subsídio teórico-metodológico no ensino de Geografia são de suma importância para as averiguações sobre as representações do espaço, na perspectiva da Geografia humanista cultural, concorda-se que estas outras cartografias que buscam a percepção, cognição e representação estão compreendidas através dos mapas mentais como uma forma de linguagem do cotidiano social e cultural que vão além da fenomenologia.

Portanto, elaborar este trabalho reforça a ideia de que a utilização de aporte metodológico da representação por meio dos mapas mentais para a percepção da paisagem vivida do aluno são ferramentas úteis com as quais os educadores de Geografia poderão contar para fazerem diagnósticos do estudo do lugar, da paisagem social, cultural, simbólicos de seus alunos e, assim, fomentar de forma instigante e mais completa os estudos de Geografia em sala de aula, promovendo novas e positivas experiências para todos em sala de aula.

\section{REFERÊNCIAS}

ALMEIDA, A. B. Abordagem fenomenológica transcendental e existencial na geografia: As bases para o entendimento do espaço vivido. Revista Geografar. Curitiba, vol.6, n.2, p.43-57, dez./2011. Disponível em:www.ser.ufpr.br/geografar. Acesso em 1 de agosto de 2016 .

ARCHELA, R. S; GRATÃO, L.H.B; TROSTDORF, M. A.S. O lugar dos mapas mentais na representação do lugar. Geografia - Londrina, vol.13 - n. 1 - Jan./Jun. 2004.

Disponível em: http://www.uel.br/revistas/geografia/v13n1eletronica/7.pdf. Acesso em 1 de agosto de 2016.

BERTIN, M. Geografia Humanística- O papel das Representações Sociais e Espaciais em Manifestações Contemporâneas. Revista Geografar- Curitiba, vol.8, n.2, p.104132, dez./2013. Disponível em:http://revistas.ufpr.br/geografar/article/view/30056/21615. Acesso em 31 de Julho de 2016. 
CLARO, L. C; PEREIRA, V. A. A postura fenomenológica enquanto contributo à pesquisa em educação. Revista Sul-Americana de Filosofia e Educação. Universidade de Brasília, n. 25:nov/2015 - abril/2016, p. 97-112. Disponível em:http://www.periodicos.unb.br/index.php/resafe/article/view/17497/12529. Acesso em 1/ de agosto de 2016.

CORRÊA, R. L. Espaço, um conceito-chave da Geografia. In: CASTRO, I. E; GOMES, P. C. C. CORRÊA, R. L. (Org.). Geografia: conceitos e temas. $2^{\mathrm{a}}$ ed. Rio de Janeiro: Bertrand Brasil, 2000.

CHAUI, M. Convite à Filosofia. São Paulo: Ática, 2000.

LIMA, A. M. L; KOZEL, S. Lugar e mapa mental: uma análise possível. GeografiaLondrina vol. 18, n. 1, jan./jun. 2009.

Disponível:http://www.uel.br/revistas/uel/index.php/geografia/. Acesso em 1 agosto de 2016.

LYNCH, K. A imagem da cidade. São Paulo: Martins Fontes,1997.

MARANDOLA JR. E. Humanismo e a Abordagem Cultural em Geografia. Geografia, Rio Claro, vol.30, n.3, p. 393-421, dez. 2005. Disponível:

http://www.periodicos.rc.biblioteca.unesp.br/index.php/ageteo/article/view/611. Acesso em 1 de agosto de 2016.

PAULA, F. C. Geografia Humanista e Fenomenologia: contribuições Francófonas no L'espace Geografaphique. Geografia, Rio Claro, vol.39, n.2, p.225-240, mai./ ago.2014.

Disponivel:http://www.periodicos.rc.biblioteca.unesp.br/index.php/ageteo/article/vie w/9315. Acesso em 1 de agosto de 2016.

GONÇALVES, A. R. Repensando o lugar na geografia: espaços- tempos cotidiano e conhecimentos e práticas sociais. GEOGRAFIA, Rio Claro, vol. 32, n. 3, p. 521-537, set./dez. 2007.

GOMES, P. C. C. Geografia e modernidade. Rio de Janeiro: Bertrand, 2010.

HUSSERL, E. A crise da humanidade europeia e a filosofia: introd. E trad. Urbano Zilles.2 ${ }^{a}$ Edição. Porto Alegre: EDIPUCRS, 2002.

MERLEAU-PONTY, M. Fenomenologia da Percepção. Tradução Carlos Alberto Ribeiro de Moura. $2^{a}$ ed. São Paulo: Martins Fontes, 1999. 662p

OLIVEIRA, L. Percepção da paisagem geográfica: Piaget, Gibson e Tuan. Geografia, Rio Claro, Vol.25(2): 5-22, agosto, 2000. Disponível em: http://www.bib.unesc.net/arquivos/75000/76600/11_76616.htm. Acesso em: 1 de agosto de 2016. 
PEREIRA, C. E. G; SEEMANN, J. (Re) apresentações cartográficas do espaço municipal mapas artísticos em deriva da cartografia escolar. Revista Geografares, Edição Especial, p.48-65, Janeiro-Agosto, 2014.

RELPH, E. C. As bases fenomenológicas da Geografia. In: Geografia. Rio Claro, vol.4, $n^{\circ}$ 7, p.1-25, Abril, 1979.

RICHTER, D. Raciocínio geográfico e mapas mentais: a leitura espacial do cotidiano por alunos do Ensino Médio. 2010. p 320.Tese (Doutorado em Geografia). Presidente Prudente: Universidade Estadual Paulista, Presidente Prudente.

TUAN, Y. F. Espaço e Lugar: a perspectiva da experiência. (Tradução de Lívia de OLIVEIRA) Londrina: Eduel, 2013. 248p. 